\title{
Construção e uso de conceitos em estudos organizacionais: por uma perspectiva social e histórica
}

\author{
Queila Regina Souza Matitz \\ Universidade Positivo \\ Fabio Vizeu \\ Universidade Positivo
}

\begin{abstract}
O objetivo central deste trabalho consiste em discutir o problema da definição conceitual no campo de estudos organizacionais das perspectivas social e histórica. Para tanto, partimos de reflexões mais abrangentes a respeito do ato de conceituar no fazer científico, passando pelo estudo da formação do léxico especializado, da sociologia da linguagem e pela descrição de aspectos referentes à historicidade dos conceitos. Assim, o conceito é considerado, ao mesmo tempo, um fenômeno socialmente referente e historicamente (re)construído, capaz de revelar diferentes estruturas sociais e sua relação com o léxico de significações que se constitui ao longo do tempo. Para dar força a nossos argumentos, discutimos exemplarmente o conceito de organização, tal qual foi constituído social e historicamente pelos sociólogos norte-americanos fundadores da área denominada "teoria das organizações". Nas considerações finais, apontamos problemas práticos que envolvem a maneira como os pesquisadores organizacionais definem os conceitos que articulam a prática científica no campo.
\end{abstract}

Palavras-chave: historicidade dos conceitos; prática científica; estudos organizacionais; conceito de organização.

\begin{abstract}
Construction and use of concepts in organization studies: towards a social and historical perspective

The aim of this paper is to discuss the problem of conceptual definition in the organizational studies field, under the social and historical viewpoints. To this end, we start from broader reflections about the act of conceptualizing the scientific work studying the formation of the specialized vocabulary of the sociology of language and the description of aspects concerning the historicity of concepts. Accordingly, the concept is simultaneously considered a phenomenon socially related and historically (re) constructed, capable of revealing different social structures and their relationship to the lexicon of meanings that was constituted throughout time. In order to support our arguments, we exemplar-
\end{abstract}

Artigo recebido em nov. 2010 e aceito em jun. 2011.

RAP - Rio de Janeiro 46(2):577-98, mar./abr. 2012 
ily argue about the concept of organization, as it was socially and historically composed by American sociologists and founders of the "theory of organizations" field. For final remarks, we point out practical problems that involve the way researchers define organizational concepts that articulate the scientific practice in the field.

KEY WORDS: historicity of concepts; scientific practice; organizational studies; concept of organization.

\section{Introdução}

Nos últimos anos, intensificou-se a preocupação na comunidade acadêmica brasileira da área de estudos organizacionais (EOR) quanto às questões epistemológicas. A recente criação de um tema específico na mais importante academia brasileira de administração para tratar desse assunto reflete essa crescente preocupação. Na verdade, o interesse pelas discussões epistemológicas em estudos organizacionais se explica, em parte, pela forma heterogênea de articulação da área, onde diferentes disciplinas e perspectivas se mesclaram para constituir o entendimento plural que atualmente se tem sobre a realidade organizacional (Burrell e Morgan, 1979). Entretanto, mesmo considerando os benefícios da multi e interdisciplinaridade no campo, há de se considerar que nem sempre os benefícios da diversidade significaram uma preocupação equivalente com o uso adequado de teorias ou conceitos emprestado de outras áreas (Whetten, Felin e King, 2009). Neste sentido, um dos grandes desafios da produção de conhecimento acadêmico de qualidade é a ampliação do entendimento crítico e reflexivo sobre esse processo, bem como sobre os problemas a ele associados.

Como afirmam Tsoukas e Knudsen (2003), sendo os pesquisadores de ciências sociais ao mesmo tempo participantes e observadores do campo investigado, esses são habilitados por sua capacidade reflexiva a enxergar possíveis ameaças à validade da produção de conhecimento proposta por sua área de estudos. E ainda, como lembram os autores, há certa obviedade no fato de que a produção do conhecimento é uma atividade social, a qual envolve não apenas o trabalho em si, mas também constante interação comunicativa. Esta última, por sua vez, permite o compartilhamento de significados por uma determinada comunidade, por meio do domínio de uma linguagem, de um conjunto de procedimentos e de um conjunto de objetos de estudo.

Atentamos aqui, particularmente, para a questão da atribuição de significado aos fenômenos observados no contexto da linguagem científica e do modo como as circunstâncias históricas condicionam o desenvolvimento, o uso e o compartilhamento de conceitos por uma determinada comunidade científica, mais especificamente, a comunidade científica que se ocupa dos estudos organizacionais. Ainda, nos detemos particularmente no estudo do conceito de organização, objeto dessa área de estudos e, conforme lembram Tsoukas e Knudsen (2003), um objeto conceitualmente dependente, cuja definição deriva de um conjunto particular e socialmente definido de interpretações e significados. Dessa forma, sujeito e objeto são espaços conceituais simétricos, pois ambos são constituídos pela linguagem. E, voltando 
à questão da validade da produção de conhecimento na área de estudos organizacionais, torna-se essencial uma reflexão específica sobre aspectos potencialmente influentes na forma como a linguagem científica é social e historicamente produzida, utilizada, compartilhada e interpretada.

O objetivo deste trabalho, portanto, é discutir o problema da definição conceitual dentro do campo de estudos organizacionais, de uma perspectiva social e histórica. Para tanto, partimos de reflexões mais abrangentes a respeito do ato de conceituar no fazer científico, passando pelo estudo da formação do léxico especializado, da sociologia da linguagem e pela descrição de aspectos referentes à historicidade dos conceitos. Além disso, considerando-se que o conceito é duplamente um fato linguístico e um indicativo de um específico contexto social (Koselleck, 1992), somente pode ser apreendido quando considerado em sua dupla natureza sincrônica e diacrônica. Assim, o conceito é, ao mesmo tempo, um fenômeno socialmente referente e historicamente (re)construído, capaz de revelar diferentes estruturas sociais em sua relação com o léxico de significações que se constitui ao longo do tempo.

O presente trabalho se justifica, pois, de acordo com Koselleck (1992), há um problema quando usamos os conceitos de forma ingênua, a partir de uma semântica a priori. Considerando-se que conceitos devem prestar-se à interpretação de material empírico, e não o oposto, novas situações e fenômenos não devem ser forçados a se submeterem à linguagem ou a um conjunto ortodoxo de conceitos e categorias. Em outras palavras, além de esforçarmo-nos a compreender as variações semânticas próprias ao uso de um determinado conceito ao longo de sua história, também devemos respeitar as interações entre apreensão linguística e realidade dos fatos, de forma a evitar distorções de significado e de representação simbólica. Assim, este ensaio foi estruturado de maneira a revelar questões fundamentais acerca dos problemas e da dinâmica de produção e uso de conceitos na comunidade acadêmico-científica. Essas questões tratadas por teorias de estudo do léxico especializado revelam aspectos complexos da relação entre formação lexical e formação do campo científico. Neste sentido, os conceitos assumem um papel fundamental na construção e reconstrução do campo acadêmico moderno (Foucault, 1999); por outro lado, a atividade social que se processa dentro do campo científico também condiciona a formação e transformação dos conceitos, afetando, por conseguinte, a própria natureza do saber produzido pela comunidade científica.

Para dar força a nossos argumentos, discutimos ao final do texto pontos selecionados a partir da discussão anterior e tendo por referência o conceito de organização, tal qual foi constituído social e historicamente pelos sociólogos norte-americanos fundadores da área denominada "teoria das organizações". Neste exercício, buscamos refletir sobre como o conceito "organização" e seus qualificadores carregaram diacronicamente a trajetória de construção do campo acadêmico de estudos organizacionais, bem como sua articulação com outras áreas disciplinares. Nas considerações finais, apontamos problemas práticos que envolvem a maneira como os pesquisadores organizacionais definem os conceitos que articulam a prática científica no campo. A partir desta consideração, apontamos também potenciais áreas de estudos dentro da linha de estudos de conceitos e da construção lexical da área de estudos organizacionais. 


\section{0 conceito no contexto do fazer científico}

Goode e Hatt (1979:56) apresentam uma discussão inicial a respeito do conceito enquanto elemento básico do método científico e lembram que "às vezes é esquecido que os conceitos são criações lógicas criadas a partir de impressões sensoriais, percepções ou, mesmo, experiências bem complexas". Conceitos, portanto, não devem ser confundidos com os fenômenos aos quais fazem referência. Além disso, conceitos só adquirem significado dentro de um determinado sistema teórico ou esquema de pensamento (Koselleck, 1992). O caráter simbólico do conceito demonstra sua utilidade no fazer científico na medida em que, ao possibilitar a existência do pensamento, torna possível estudar, organizar, isolar e comparar propriedades dos objetos da experiência sensorial.

Ainda, ao possibilitar o pensamento, os conceitos permitem a comunicação humana e, portanto, são também os elementos essenciais da comunicação científica: "Como, porém, a ciência exige maior precisão da comunicação, o processo de conceptualização deve ser muito mais conscientemente uma parte da ciência do que da maioria dos contextos do senso comum e da vida diária" (Goode e Hatt, 1979:57). Outro atributo dos conceitos no campo científico merece destaque: a capacidade de resumir uma quantidade significativa de informação. Dessa forma, se torna dispensável a reconstrução contínua da complexidade abstraída dos objetos de estudo da ciência e de suas inter-relações teóricas.

Por outro lado, conceitos podem criar problemas comunicativos quando um mesmo termo é utilizado simultaneamente por quadros de referência distintos. Por exemplo, pode-se citar o caso de "burocracia", o qual assume distintos significados quando definido por sociólogos ou por leigos, no sentido conferido pelo senso comum. E, ainda, é preciso considerar a possibilidade de mudança dos conceitos, na medida em que o conhecimento em torno de determinado fenômeno se aperfeiçoa ou se modifica. Uma das principais tendências nesse sentido seria a substituição de um conceito mais amplo por conceitos mais específicos, resultantes de uma melhor compreensão a respeito das múltiplas facetas de um mesmo fenômeno.

Finalmente, tem-se a questão do nível de generalização do conceito. Ou seja, conceitos podem variar em relação ao grau de "concretude" dos fenômenos aos quais fazem referência. Dessa forma, à ciência cabe a tarefa de relacionar com fecundidade o abstrato e o concreto, o geral e o específico, o abrangente e o restrito. Cabe à ciência, ainda, esclarecer conceitos que fazem parte da definição de outros conceitos, buscar a integração entre diferentes níveis teóricos, além de desenvolver os métodos apropriados de operacionalização e mensuração de conceitos.

Para o cientista social, um conceito é uma abstração a partir da percepção de fenômenos ou eventos ou, ainda, uma representação resumida de uma diversidade de fatos (Selttiz et al., 1974). Esta natureza agregadora dos conceitos é particularmente relevante para as ciências sociais, pois contribui para a simplificação do pensamento em diversos graus de aproximação em relação aos objetos ou fatos que representa. Ao conceituar, o indivíduo é capaz de agrupar e ao mesmo tempo diferenciar características dos objetos sob observação. E, quanto 
mais elevado o nível de abstração do processo de conceituação, mais distante o conceito se torna em relação ao referente concreto.

Conceitos de alto grau de abstração são também chamados construtos, uma vez que são construídos a partir de conceitos de nível inferior de abstração. Construtos, portanto, são tipos de conceitos e demandam maior cuidado na sua definição: "Quanto maior a distância entre os conceitos e os fatos empíricos a que pretendem fazer referência, maior a possibilidade de tais conceitos serem mal compreendidos ou mal empregados, e maior o cuidado necessário para sua definição" (Selttiz et al., 1974:49). Gellner (1986:232) também explica o desafio do uso dos conceitos nas ciências sociais: "Os debates sobre conceitos nas ciências sociais tendem a ser um problema de escolha de termos e, o que é mais importante, de suas definições. Pode-se falar da descoberta ou da invenção de conceitos; e também da substituição ou desenvolvimento de conceitos". Finalmente, a realização de pesquisas empíricas e a criação de teoria também contribuem para esclarecer e reformular conceitos. Ao escolher indicadores (ou indícios concretos) representativos do conceito abstrato, o próprio conceito pode ser revisto, ampliado, reformulado.

Em resumo, conceitos são essenciais no campo científico por possibilitarem a discriminação entre fenômenos e, ainda, a realização de operações de medição e classificação, enfim, o estabelecimento de relações entre esses fenômenos. E, para sistematizar o uso e a evolução dos conceitos nos campos científicos, um corpo de disciplinas especializadas no estudo do léxico, entre essas a terminologia e a socioterminologia, buscam contribuir para a compreensão da constituição e funcionamento dos léxicos especializados. No próximo subitem discutimos as principais contribuições dessas áreas de estudos.

\section{As ciências do léxico e o estudo do léxico especializado}

De acordo com Krieger e Finatto (2004), o interesse dos linguistas sobre a constituição e o funcionamento dos termos técnico-científicos é recente e pode ser situado na última década do século XX. Enquanto campo de estudos, a terminologia tem como objeto de estudo o léxico especializado. Sob o ponto de vista dessa disciplina, uma ciência só passa a existir na medida em que identifica, denomina e impõe seus conceitos. Ou seja, a legitimidade de uma ciência está intrinsecamente ligada à denominação de seus objetos, os quais, consequentemente, podem então servir à realização de inferências e à construção de teorias baseadas em relações entre conceitos. Ao mesmo tempo, a definição terminológica constitui objeto de estudo da terminologia. Devido à sua herança lógico-filosófica, o estudo das definições terminológicas no campo da terminologia tem como objetivo central a verificação da correção lógica e/ou de suas condições de verdade.

Neste sentido, a terminologia é uma disciplina de compreensão epistemológica, já que se ocupa do estudo pormenorizado do léxico de cada área específica do conhecimento humano: "A terminologia pressupõe uma teoria da referência, ou seja, uma correlação entre a estrutura geral do conhecimento e o código linguístico correspondente" (Biderman, 2001:19). 
Em outras palavras, a terminologia busca estabelecer uma relação entre estrutura conceitual e estrutura lexical da língua. Ocupa-se, portanto, a partir de um processo onomasiológico, da natureza do conceito, das relações conceituais, da relação termo-conceito e da atribuição de termos aos conceitos.

A terminologia chama a atenção para o caráter ao mesmo tempo necessário e limitante da língua em relação ao registro e transmissão do conhecimento. Ou seja, "No espaço contínuo do conhecimento, a função referencial da linguagem mapeia um repertório discreto e enumerável de símbolos - o léxico" (Biderman, 2001:20). Ainda, enquanto seja relativamente simples o ato de atribuir termos a conceitos, é difícil especificar os limites da conceituação, gerando atribuições referenciais múltiplas e não coincidentes em relação a fenômenos e eventos do universo cognoscível. Para minimizar este problema, propõe-se, no campo da terminologia, uma normalização que garanta aos termos científicos significados únicos. Trata-se de garantir eficácia à comunicação científica.

Ao mesmo tempo, surge uma preocupação com o respeito devido às variantes terminológicas decorrentes de espaços socioculturais e linguísticos específicos, os quais propiciam diversas manifestações terminológicas na forma como um determinado conceito se apresenta. A ideia de "harmonizar" surge nesse contexto, ao sugerir um método de normalização que busca "pôr em correspondência os termos uns com os outros no seio da mesma língua e entre línguas, gerenciando os usos" (Faulstich, 2006:28). A teoria da variação terminológica, portanto, admite que os termos assumem funções específicas nas línguas de especialidade, de acordo com o contexto de uso. Ou seja, uma língua pode sofrer mudanças decorrentes do tempo histórico, da origem geográfica ou social e dos contextos em que se encontram os locutores.

No contexto da socioterminologia, principalmente em função de suas origens no cruzamento da sociologia da linguagem com a harmonização linguística, se defende a abordagem do funcionalismo linguístico como aquele que mais se adequa ao estudo da terminologia nas línguas de especialidade, especialmente na medida em que assume uma postura mais descritiva e menos prescritiva. Ainda sob este ponto de vista, os fenômenos linguísticos variáveis somente podem ser avaliados a partir de um corpus textual, de preferência especializado. Dessa forma, é possível estudar quais termos variam e como variam. Além disso, é possível estudar os termos a partir das condições de circulação do termo no funcionamento da linguagem, assim como estudar o termo sob a perspectiva linguística na interação social. A compreensão da mudança terminológica como mecanismo resultante da pragmática discursiva torna-se, portanto, o objetivo central da socioterminologia:

(...) a pesquisa socioterminológica deverá considerar que os termos, no meio linguístico e social, são entidades passíveis de variação e de mudança e que as comunicações entre membros da sociedade são capazes de gerar conceitos interacionais para um mesmo termo ou de gerar termos diferentes para um mesmo conceito. (Faulstich, 2006:30)

A fonte natural de onde emergem os termos usados nas comunicações entre profissionais são os discursos de natureza científica, técnica e vulgar (Faulstich, 2006). Entretanto, é 
na interface entre esses discursos, que, dado os atributos distintivos dos espaços sociais que os produzem, se estabelece o próprio saber do cientista, a despeito da especificidade do seu léxico conceitual e terminológico e do papel deste na própria definição do campo científico. A compreensão do processo de formação do léxico especializado, discutido a seguir, pode contribuir para esclarecer esses aspectos.

\section{Conceitos, termos e definições terminológicas: a formação do léxico especializado}

Cada campo científico é organizado por uma estrutura de conceitos referentes aos processos e objetos mais importantes a serem estudados. Esses conceitos, por sua vez, são mencionados e transmitidos sob a forma de termos, formando um vocabulário dinâmico e especializado da área. "Por conseguinte, a principal tarefa em qualquer ciência é desenvolver um sistema de classificação, uma estrutura de conceitos, um conjunto cada vez mais preciso de definições para esses termos" (Goode e Hatt, 1979:14). O sistema teórico de uma ciência pode ser considerado, portanto, um sistema conceitual.

Conceitos são símbolos que correspondem ao significado de termos, embora não se constituam em entidades linguísticas no sentido restrito. Conceito, portanto, não é sinônimo de palavra (Koselleck, 1992). Conceitos são transmitidos por meio de palavras — ou termos - , as quais lhes conferem materialidade comunicativa. Os termos, conforme explica Faulstich (2006:28), são:

(i) signos que encontram sua funcionalidade nas linguagens de especialidade, de acordo com a dinâmica das línguas; (ii) entidades variantes, porque fazem parte de situações comunicativas distintas; (iii) itens do léxico especializado que passam por evoluções, por isso devem ser analisados no plano sincrônico e no plano diacrônico das línguas.

Definições terminológicas são tipos específicos de definições — em sentido mais amplo — e estão diretamente relacionadas ao significado de termos ou expressões no contexto de uma determinada ciência. Representações conceituais vinculadas a saberes científicos, portanto, constituem manifestações de estruturas conceituais compartilhadas entre os membros de uma comunidade científica. O ato de definir é, ao mesmo tempo, um ato de inclusão e de exclusão, na medida em que determina fronteiras de significação em torno de categorias de objetos, eventos, fenômenos, enfim, dos elementos sobre os quais se propõem teorias, hipóteses e relações.

A definição ocupa um lugar central em todas as ciências. O ato de definir é essencial, por exemplo, ao estabelecimento de relações entre coisas e ideias (Foucault, 1999). Em Aristóteles, encontramos a ideia de "discurso de limitações", a qual tem sido traduzida por "definição". Em sentido estrito, uma definição deveria ser capaz de abranger todos os usos da palavra em determinada época, além de permitir distingui-la de outras palavras, incluindo 
suas equivalentes semânticas. E, ao contrário das definições linguísticas polissêmicas utilizadas na língua comum, espera-se que o uso dos termos no contexto científico seja restrito a um único significado, permitindo o estabelecimento de relações e a comparação entre fenômenos (Sager, 2000; Rey, 2000).

A qualidade da relação entre definição terminológica e conceito depende das condições de apreensão do significado do objeto e de sua consequente "tradução" em termos linguísticos, evitando-se a tautologia. Trata-se, portanto, de um problema secular: o da relação entre a semântica da linguagem natural e a construção de ferramentas de significação úteis e necessárias ao desenvolvimento do pensamento científico. O ideal, de acordo com Pascal, por exemplo, seria o uso estrito da linguagem matemática para uso científico. Entretanto, conforme lembra Rey (2000), a teoria da definição passa por uma mudança importante quando passa a usar a definição como forma de explicar a natureza do objeto não na forma como é, mas na forma como é concebido (Foucault, 1999). É o movimento da ontologia em direção à psicologia cognitiva, particularmente importante para estudos de produção e transferência de conhecimento. Trata-se, portanto, da necessidade de definir critérios para o uso da linguagem, com base nos objetivos desse uso.

O léxico de uma língua natural, assim, corresponde ao conjunto das palavras utilizadas para nomear objetivos e fenômenos. E, ao nomear os resultados de sua percepção sobre a realidade, o homem inicia simultaneamente um processo de classificação desses mesmos objetos e fenômenos. Nomeação, portanto, pode ser considerada como a primeira etapa no percurso científico do conhecimento. A geração do léxico, assim, corresponde a um processo de observação de semelhanças e diferenças, em atos sucessivos de cognição e de categorização da experiência.

Sob esse ponto de vista, os conceitos são modos de ordenação e estruturação dos dados sensoriais sob a forma de signos lexicais. Pode-se supor, portanto, que a ampliação da capacidade de observação e de identificação de semelhanças e diferenças entre os fenômenos é seguida por uma ampliação correspondente do léxico das línguas naturais. Dessa forma, o léxico corresponde a um sistema aberto (Biderman, 2001).

No caso do léxico especializado, considera-se ao mesmo tempo a dimensão cognitiva e a dimensão linguística dos termos utilizados em cada área do conhecimento. Em outras palavras, faz parte do estabelecimento da legitimidade de um campo científico a identificação de seus objetos - sua dimensão cognitiva — e a denominação de seus objetos — sua dimensão linguística. E, ainda, cite-se a função comunicativa dos termos, ao representar e transmitir o saber científico e técnico. Idealmente, os termos técnico-científicos deveriam privilegiar a precisão conceitual ao serem considerados como signos linguísticos de valor monossêmico, caracterizados pela monorreferencialidade, veiculantes dos significados específicos de cada área (Krieger e Finatto, 2004). Entretanto, conforme observado na conclusão do subitem anterior, os termos usados nas comunicações profissionais sofrem influências de outros campos linguísticos, de outras áreas do conhecimento, de outros contextos, de outras épocas, enfim, não estão imunes às interferências externas que motivam, por exemplo, a polissemia dos conceitos mais essenciais a cada área de estudos e, em particular, à área de ciências sociais. 


\section{A historicidade dos conceitos: anacronismo e condição histórica do intérprete}

Outro aspecto problemático dentro da análise de construção social dos conceitos é a negação de sua historicidade. Neste sentido, seguimos o mesmo entendimento daqueles que defendem a relatividade histórica dos conceitos dentro do léxico especializado de grupos sociais. Na verdade, dizer que os conceitos apresentam um sentido para determinado grupo historicamente situado - ou seja, um grupo social específico no tempo e no espaço - significa que, para outro grupo social, este conceito tem outro sentido, ou, de maneira mais radical, não existe. Isso porque, quando grupos sociais historicamente distintos se referem à mesma palavra, isso não equivale a dizer que a palavra é utilizada para referir o mesmo conceito, pois este está vinculado ao contexto sócio-histórico de constituição e desenvolvimento da comunidade linguística de referência.

É por isso que, para Koselleck (1992), principal proponente da chamada história conceitual, é preciso distinguir entre palavra e conceito. Enquanto cada palavra remete a um sentido ou conteúdo, conceitos demandam ao mesmo tempo uma formulação e uma interpretação teórica, reflexiva. Conceitos, portanto, envolvem graus de teorização/abstração necessários ao desenvolvimento de expressões capazes de conter de forma sintetizada e abstrata uma teoria acerca de um fenômeno concreto. O conceito é generalizante o suficiente para assumir o significado que vai além do fato isolado e surge a partir de um processo de abstração e agregação. O conceito permite, ao mesmo tempo, apreender/compreender o fato concreto e, posteriormente, atuar sobre o mesmo.

Koselleck (1992) apresenta ainda a ideia de que todo conceito só pode enquanto tal ser pensado e falado/expressado uma única vez. Ou seja, para cada formulação teórica/abstrata expressa sob uma forma linguística corresponde uma situação concreta que é única. E, embora os conceitos - e os termos pelos quais são expressos - possam ser utilizados em épocas e situações diversas, seu conteúdo altera-se substancialmente. Há que se ter cuidado, portanto, com o caráter único (einmalig), articulado ao momento de sua utilização.

Ao mesmo tempo, tudo o que se disser só será compreensível na medida em que houver conhecimento prévio da semântica, pois sem o conhecimento prévio do significado das palavras nada será compreendido. A semântica é, assim, imprescindível para a comunicação linguística (Sprachhandlung) e para o uso pragmático da língua. Em outras palavras, a diacronia está sempre contida na sincronia, o que permite e justifica uma história dos conceitos. Como afirma Koselleck (1992:139), "ela [a histórica dos conceitos] pode ser escrita, posto que em cada utilização específica (situative Verwendung) de um conceito, estão contidas forças diacrônicas sobre as quais eu não tenho nenhum poder e que se expressam pela semântica". A duração da semântica, portanto, é um tema de suma importância para a construção da história dos conceitos, principalmente sob o ponto de vista metodológico. Para tanto, ou seja, para possibilitar a mensuração da diacronia, Koselleck propõe a descrição sistemática das estruturas temporais de três grupos de fontes (textos), de forma a apreender estruturas repetitivas indicativas de forças diacrônicas ou ocasiões de uso não repetitivo da semântica. Esses três grupos de fontes seriam constituídos por (a) fontes da linguagem do cotidiano (car- 
tas, jornais, documentos etc.), (b) dicionários e enciclopédias, principalmente comparando-se alterações de significado ou inovações e sentido em diferentes línguas e (c) obras textuais inalteradas no decorrer de suas sucessivas edições, tais como a obra de um filósofo, a Bíblia, as obras poéticas, enfim, os textos clássicos de diferentes campos do saber.

Se para a história conceitual interessa problematizar o processo do surgimento de conceitos a partir de procedimentos de teorização, da mesma forma que é caro a essa disciplina situar os contextos linguísticos originais de formação teórica das ideias das quais derivam os conceitos, também o é identificar a trajetória histórica de reconstrução dos conceitos, especialmente quanto à identificação da intersecção entre diferentes campos disciplinares e contextos histórico-culturais distintos. No caso da história conceitual de Koselleck, esta preocupação com a trajetória histórica dos conceitos remete a uma dívida com a hermenêutica de Gadamer, que considera a relação entre texto, contexto e interpretação o cerne da compreensão das ideias, entre essas, o conceito (Jasmin, 2005).

Gadamer aponta como fundamental para a compreensão do conhecimento e seu processo de construção social a condição histórica do intérprete. Contrapondo-se radicalmente à perspectiva do contextualismo linguístico inglês, que vê na intenção original do autor do texto o mecanismo essencial para se evitar o problema do anacronismo (Jasmin, 2005), Gadamer aponta para a centralidade da experiência histórica no processo de construção, transmissão e interpretação do saber. Referindo-se às diferenças entre a postura histórica privilegiada do leitor de um texto passado em relação àquela assumida pelo autor, Gadamer revela o verdadeiro lugar da experiência histórica no processo de (re)construção do contexto linguístico:

O fato de que a compreensão ulterior possua uma superioridade de princípio face à produção originária e possa, por isso, ser formulada como um "compreender melhor", não repousa, na verdade, sobre um tornar consciente posterior, capaz de equiparar o intérprete com o autor original (...), mas, ao contrário, reporta a uma diferença insuperável entre o intérprete e o autor, diferença que é dada pela distância histórica. Cada época tem de entender um texto transmitido de uma maneira peculiar, pois o texto forma parte do todo da tradição, na qual cada época tem um interesse pautado na coisa e onde também ela procura compreender-se a si mesma. O verdadeiro sentido de um texto, tal como este se apresenta ao seu intérprete, não depende do aspecto puramente ocasional que representam o autor e seu público originário. Ou pelo menos, não se esgota nisso. Pois esse sentido está sempre determinado também pela situação histórica do intérprete, e, por consequência, por todo processo objetivo histórico. (Gadamer, 1997:443-444)

Assim, o contextualismo linguístico defendido pela história conceitual une a dimensão social de interpretação sincrônica - aquilo que costuma denominar por intersubjetividade — com a dimensão diacrônica dos conceitos, tendo em vista que estes representam um saber herdado do passado, no mesmo sentido que é o presente um saber interpretado coletivamente por uma mesma comunidade linguística. É por este motivo que, para a história dos conceitos, não importa o conceito em si mesmo - este não é uma verdade absoluta, uma entidade independente, como gostariam os essencialistas — , importa a história por trás dos conceitos, 
na qual se acessa o verdadeiro tema de interesse do historiador, ou seja, a sociedade. Como afirma Jasmin (2005:32), no registro da história conceitual, "é possível afirmar, rigorosamente, que os conceitos em si não têm história; mas também é possível afirmar, com rigor, que a sua recepção tem".

\section{Situando o problema da construção e do uso dos conceitos em EOR sob uma perspectiva social e histórica}

De uma perspectiva social e histórica de construção e uso de conceitos, a dinâmica do fazer científico nos estudos organizacionais e sua consequente produção de conhecimento podem ser observadas a partir de problemas específicos, que refletem, antes de tudo, as próprias especificidades deste campo social. O primeiro deles se articula como reflexo da diversidade temática e o consequente intercâmbio entre o campo de estudos organizacionais e outras especialidades acadêmicas, originárias de diferentes áreas disciplinares. Esse intercâmbio leva a uma dinâmica específica, onde se pratica uma espécie de empréstimo teórico-conceitual frouxo entre estes diferentes campos disciplinares (Whetten, Felin e King, 2009). O problema desta prática de fazer científico é justamente a dificuldade em se formar adequadamente um léxico especializado para estudos organizacionais capaz de precisar seu universo linguístico próprio, se não pela formação/criação de termos únicos, pelo menos pela construção de definições terminológicas originais. De certa forma, este problema já foi apontado antes por Ramos (1989), por meio da ideia de colocação inapropriada de conceitos, vista como algo perigoso para a identidade e capacidade reflexiva da área de estudos organizacionais. Assim afirma o autor:

O campo da teoria da organização tem sido tão indiscriminadamente receptivo a influências vindas de tantas áreas diferentes de conhecimento que parece agora ter perdido a consciência de sua missão específica. Embora um relacionamento cruzado entre as disciplinas seja, de modo geral, positivo e mesmo necessário à criatividade, é hora de uma séria avaliação da condição desse campo, para que ele não se transforme numa mera confusão de divagações abstratas, desprovidas de força e direção. Toda disciplina deve ter um mínimo de intolerância em suas transações com as outras, ou perderá sua razão de ser. Ter identidade e caráter é, num certo sentido, ser intolerante. (Ramos, 1989:69)

A intolerância defendida por Ramos para a área de estudos organizacionais pode ser entendida como a busca por maior especificidade do conteúdo léxico da área. Como foi observado, além de representar um elemento importante para a formação do campo acadêmico-científico enquanto grupo social delimitado, esta identidade linguística é necessária para orientar a maneira pela qual se constrói o saber científico deste campo. Este duplo esforço é claramente observado no ensaio de Emile Durkheim sobre "as regras do método sociológico", em que esse autor - considerado um dos fundadores da sociologia — pretendeu delimitar, ao 
mesmo tempo, a especificidade do campo disciplinar e a forma de condução do fazer científico deste campo. Para tanto, Durkheim (1995) tece composições terminológicas fundamentais de orientação léxica, como o conceito de "fato social".

Outro problema referente à maneira pela qual se constituem as referências teóricoconceituais em estudos organizacionais diz respeito à forte presença neste campo acadêmico de um discurso pragmático de natureza não acadêmica. Observando-se a trajetória histórica de formação do campo, percebe-se facilmente o quanto somos devedores dos pragmáticos da administração, "os engenheiros da organização" (Wahrlich, 1986:9), especialmente daqueles que articularam os movimentos doutrinários fundadores do Management (Taylor é o mais lembrado, mas não é o único, tão pouco o seu movimento de Scientific Management), onde os problemas teorizados e os conceitos advindos deste esforço eram definidos exclusivamente por questões práticas de controle e eficiência do trabalho (labor) em organizações econômicas da virada do século XIX para o século XX (Vizeu, 2008).

De certo modo, a transmissão de saberes e o esforço de definição conceitual por não acadêmicos, bem como a legitimação dessa prática por parte dos acadêmicos da área de estudos organizacionais contribuem para a imagem frouxa que se faz quanto à imprecisão do léxico especializado nessa área. É claro que não se defende aqui a elitização da produção do saber em administração, nem a ideia de que a produção conceitual empreendida exclusivamente por acadêmicos é superior àquela empreendida pelo senso comum dos não acadêmicos; apenas se aponta para o problema de que o saber científico se constitui especialmente pelos processos de delimitação lexicográfica na qual as práticas científicas de construção do conhecimento são relevantes. Ora, são justamente tais práticas aquelas abandonadas pelos não acadêmicos em seu fazer conceitual. Por vezes, a falta de delimitação clara entre os discursos científicos, técnicos e vulgares na produção do conhecimento acadêmico de estudos organizacionais é buscada no sentido de aproximar o universo prático da administração de organizações e a academia interessada na construção do saber cientificamente orientado desse fenômeno, mas tem por ônus a descontinuidade léxica e a falta de identidade acadêmica, muitas vezes lembrada por acadêmicos de outras especialidades, como a sociologia e a antropologia.

Outra questão importante diz respeito a um viés dos pesquisadores da área, ao constituírem uma perspectiva que desprivilegia a história na produção do conhecimento sobre organizações e administração. Essa tendência foi apontada por Vizeu (2010) como uma herança do funcionalismo sociológico, uma abordagem presente desde as primeiras sistematizações teóricas que assinalaram decisivamente a formação do campo de estudos organizacionais, e que ainda corresponde à epistemologia predominante na área. O campo de estudos organizacionais herdou do funcionalismo sociológico a tendência de privilegiar o conhecimento universal, ou seja, aquele que reflete características e/ou princípios supostamente gerais, que se manifestam na realidade social independentemente das peculiaridades do contexto espaço-temporal. É desta premissa que Vizeu (2010) indica advir a perspectiva a-histórica do campo, que se manifesta especialmente na universalização de conceitos que, se observados com cautela, são historicamente situados. Este problema nada mais é do que a tendência ao anacronismo conceitual e teórico. 
Uma prática comum na produção do conhecimento em estudos organizacionais reflete emblematicamente esse anacronismo conceitual. Na construção dos quadros teóricos de referência dos trabalhos da área observa-se o hábito de reunir definições terminológicas de autores de diferentes contextos históricos. Nessa prática, não fica evidente alguma preocupação em situar historicamente os autores, e os diferentes conceitos são conjugados indiscriminadamente, sem atenção para o sentido dado por autores de diferentes épocas ou mesmo de variados contextos nacionais. No Brasil, observa-se essa prática especialmente em trabalhos de dissertação de mestrado e de doutorado. Ou seja, é comum nesses trabalhos que se comparem definições de autores do início do século passado e outros contemporâneos, sem nenhuma consideração para com as discrepâncias que tais definições possam apresentar em relação ao distanciamento histórico entre os autores. Como observamos acima, o anacronismo se estabelece pela leitura indevida das representações do passado, onde estas são consideradas com os olhos do presente (Jasmin, 2005). Muitas vezes, para dar sentido às discrepâncias evidentes que esta junção indiscriminada de ideias advindas de diferentes contextos linguísticos possa provocar, os pesquisadores de estudos organizacionais se valem de interpretações livres das ideias dos autores, o que intensifica a percepção quanto à falta de precisão no ato de definir conceitos nesta área. Isso é apontado especialmente por acadêmicos membros das comunidades linguísticas originárias dos conceitos emprestados, que se levantam contra tais interpretações livres e descompromissadas. Na literatura de estudos organizacionais é comum encontrarmos textos endereçados a essa defesa lexical, como aquela referente ao conceito de cultura tal qual foi concebido na antropologia (Aktouf, 1994).

\section{Um exercício de compreensão do léxico especializado em estudos organizacionais: o conceito de "organização" no contexto de formação do campo de teoria das organizações}

No sentido de realizar um exercício mental capaz de sinalizar os pontos abordados pelo presente ensaio, seguimos com a reflexão acerca de um conceito em particular no campo de estudos organizacionais. Sem pretensão de realizar uma investigação exaustiva e empiricamente profunda, esse esforço visa, antes, apontar as múltiplas dimensões que envolvem a análise da formação do léxico especializado no campo, bem como a historicidade da produção e reprodução de conceitos centrais a esse campo em particular. Para tanto, escolhemos aquele que talvez seja o conceito mais caro para o campo de teorias organizacionais, o conceito de "organização". Quanto à formação vernacular do termo, pode-se afirmar, inicialmente, que a formação e a adoção de termos nos domínios de especialidade é reflexo da constante renovação lexical que se processa em cada área do conhecimento. Entre os processos vernaculares de formação lexical destacam-se a derivação — tanto sufixal como prefixal — e a composição, quando dois termos são usados de forma composta. No caso de termos formados com o sufixo "-ção", trata-se de um caso de derivação cujo conteúdo correspondente consiste na ideia de 
"ação, processo" (Alves, 2006). "Organização", portanto, é um termo que denota a ideia de ação e de processo.

Trata-se, ainda, de um caso de empréstimo semântico, o qual ocorre quando um termo migra de um léxico mais geral para um domínio específico ou "por termos que migram de um domínio a outro, em razão de um traço comum” (Alves, 2006:33). Nesse caso, observamos o empréstimo do radical "organismo", originário da biologia, e que pode ser definido como um "sistema vivo de partes mutuamente adaptadas que funcionam juntamente para manter um todo unitário" (Hoebel, 1986:841). A esse tipo de elemento, o organismo, são atribuídas funções como reprodução, crescimento, reação, adaptação, entre outras. A ideia de organismo e organização é utilizada em diversas ciências — biologia, psicologia, psicologia social, antropologia, economia - para explicar processos relacionados ao desenvolvimento. Organismo, ainda, implica a ideia de unidade composta de partes que interagem entre si e possuem uma finalidade comum.

Ainda de acordo com Alves (2006), uma das características da formação lexical dos domínios de especialidade é a criação de termos sintagmáticos, nos quais um termo determinado é expandido por um adjetivo ou um sintagma preposicional. Desse modo, a partir do termo genérico organização, surgiram derivações, como exemplificam Boudon e Bourricard (1993:409, grifos do autor): "Sob o termo único de organização se acham designadas formas de cooperação e de coordenação totalmente diferentes. (...) Somos levados assim a distinguir e a classificar várias espécies de organização: as organizações burocráticas, as organizações econômicas e os que os americanos chamam de non profit organizations".

\subsection{Organismo social e organização social}

Particularmente em ciências sociais, o conceito de organismo é utilizado como analogia para os sistemas sociais. Como lembra Hoebel (1986:842): “em muitos aspectos os problemas apresentados para a ciência biológica e a ciência social são fundamentalmente análogos: a) problemas de estrutura e funções dos sistemas orgânicos e sociais; b) problemas de origem e desenvolvimento dos sistemas orgânicos e sociais - evolução biológica e cultural". E, no decorrer da história da filosofia e da política social, a ideia de organismo social ganha destaque, principalmente para explicar e justificar o conceito de Estado como entidade integrada por indivíduos interdependentes, cuja missão consiste em alcançar a justiça e o aperfeiçoamento moral dos homens (López, 1986). Com o tempo, somam-se novos sentidos para a concepção de organismo social, com foco nas manifestações culturais do todo orgânico sob a forma de criações do direito, da literatura, das artes, entre outras.

A ideia de organismo social e sua analogia com os organismos biológicos também é adota pelos fundadores da sociologia e da antropologia no início do século XX, em particular Comte, Taylor, Morgan e Spencer: surgem então os conceitos de diferenciação interna, especialização, interdependência, função, estrutura. 
Quanto ao termo organização social, é possível encontrar raízes históricas e teóricas na antropologia e na sociologia. No sentido antropológico, diz respeito aos agrupamentos sociais, suas funções e suas instituições. O foco dos estudos antropológicos é ao mesmo tempo o sistema ordenado de relações de obrigações intragrupos e entre grupos, além dos papéis e posições dos indivíduos e grupos dentro de sistemas mais amplos de relações (Morris, 1986; Faris, 1986). Na sociologia, a organização social designa ao mesmo tempo uma estrutura e um processo:

Como estrutura, uma organização é qualquer padrão estável de inter-relações de partes componentes, padrão esse que forma um todo que possui características não manifestas nas partes consideradas isoladamente. Assim, uma molécula, uma água-viva ou uma empresa comercial podem ser englobadas nessa definição geral. Como processo, o termo organização é usado com referência ao modo pelo qual se formam essas entidades. (Faris, 1986:847)

Uma organização social, portanto, é um conjunto de componentes (pessoas ou grupos), cujas características não são encontradas em suas partes. As organizações sociais evoluem e possuem como uma de suas características o desempenho de funções relativamente duradouras e mais eficientes do que se estivessem sendo desempenhadas por pessoas ou grupos não organizados. Considera-se, ainda, que as funções são determinantes das formas organizacionais sociais e também que estabilidade e mudança são características da necessidade de adaptação organizacional.

\subsection{Organizações e teoria das organizações}

Segundo Rios (1986), o termo organizações tem, em geral, duplo sentido: um primeiro ligado à ideia de ordem, de sistematização, e um segundo ligado ao resultado de um processo social de coordenação do trabalho. Sob o ponto de vista da teoria das organizações, interessa o segundo sentido, o da formação e funcionamento de empresas e órgãos públicos, assim como os agrupamentos de organizações. As organizações são reconhecidamente importantes em função de se constituírem em espaços de concentração de recursos econômicos e sociais. Passam a ser, portanto, centros de poder e de influência sobre outras formas e níveis de organização social.

Em Weber, o termo organização significa "um sistema de atividade contínua e intencional de um tipo específico", que tem conexão com grupos corporativos e sua administração (Morris, 1986:847). O termo passa, portanto, a relacionar-se diretamente com a atividade econômica e com o uso dos meios de produção. "A nova ciência das organizações", nas palavras de Ramos (1989), passou a estudar fenômenos relacionados à organização, entre esses: a questão da produtividade e da eficiência, o conceito de burocracia, a gestão, a tecnologia, a estrutura organizacional, a racionalização e a divisão do trabalho, a motivação, a liderança, a comunicação, a mudança, a cultura, os grupos formais e informais, o conflito e o consenso. De 
base multidisciplinar, a teoria das organizações e também as próprias organizações passaram a ser objeto de interesse e de crítica ao longo do século XX e início do século XXI.

Embora o fundamento da teoria das organizações seja frequentemente atribuído à teoria da burocracia de Weber, a esta faltam elementos considerados por conceitos modernos de organização, tais como os mencionados qualificadores (formais e informais, funcionais e não funcionais). Ou seja, aos critérios de eficiência exclusivamente racionais foram adicionados outros elementos caracterizadores das formas organizacionais. A rigor, a chamada teoria moderna da organização nasce com base no conceito de organização originado na teoria dos sistemas de Bertalanffy, conforme apontado por Etzioni (1973). O autor também indica o fato de que a teoria da organização é acusada de não levar em conta o aspecto histórico das organizações e as diferenças entre os diversos tipos de organizações e seus respectivos ambientes.

\subsection{Uma análise sócio-histórica do conceito de organizações em teoria das organizações: o ponto de vista funcionalista-estruturalista dos receptores de Parsons}

Para realizar a análise sócio-histórica do conceito de "organização" no campo de estudos organizacionais, a primeira tarefa é delimitar o corte histórico a ser investigado. Isso porque, ao longo da breve história de formação desse campo acadêmico, encontramos diferentes debates teóricos acerca do conceito. A maneira pela qual podemos delimitar historicamente um destes momentos é justamente reconhecendo o papel central da busca por uma definição conceitual mais precisa ou inovadora, de tal forma que permita situar lexicamente o campo acadêmico de teorização e investigação social. Assim, optamos por definir o corte histórico da análise no período de meados do século XX, quando um grupo de sociólogos norte-americanos, influenciados pela recepção feita por Parsons à obra de Weber, vislumbram na ideia de burocracia deste último autor a delimitação de um novo campo de estudos da sociologia. Para delimitar este campo disciplinar, elencou-se o termo "organização", o qual, além de ter sido utilizado como qualificador da nova disciplina "teoria da organização" (também reconhecida como "sociologia da organização"), foi objeto de intenso esforço teórico.

Apesar de não ser possível afirmar que o campo dos estudos organizacionais se inaugura neste esforço, é correto pensar que é a partir dele que a área ganha contornos mais acadêmicos. Isso porque, se antes o conceito de organização era objeto de interesse apenas dos engenheiros industriais e administradores profissionais, estes o fizeram de maneira a atender minimamente à prescrição de princípios e métodos de trabalho prático, sem grande preocupação com a profunda teorização a respeito (Wahrlich, 1986). Com o advento dos sociólogos, a reflexão teórica sobre o que é a "organização" ganha um novo contorno, dado, especialmente, pela formação funcionalista-estruturalista de seus proponentes. Neste sentido, a precisão na definição de "organização" foi buscada como um elemento articulador do campo, como sugere o trecho extraído de um importante texto deste período: 
As organizações são unidades sociais (ou agrupamentos humanos) intencionalmente construídas e reconstruídas, a fim de atingir objetivos específicos. Incluem-se as corporações, os exércitos, as escolas, os hospitais, as igrejas e as prisões; excluem-se as tribos, as classes, os grupos étnicos, os grupos de amigos e as famílias. As organizações caracterizam-se por: 1) divisões de trabalho, poder e responsabilidades de comunicação, que não são causais ou estabelecidas pela tradição, mas planejadas intencionalmente a fim de intensificar a realização de objetivos específicos; 2) a presença de um ou mais centros de poder que controlam os esforços combinados da organização e os dirigem para seus objetivos; esses centros de poder precisam, também, reexaminar continuamente a realização da organização e, quando necessário, reordenar sua estrutura, a fim de aumentar sua eficiência; 3) substituição do pessoal, isto é, as pessoas pouco satisfatórias podem ser demitidas e designadas outras para as suas tarefas. A organização também pode recombinar seu pessoal, através de transferência e promoções. (...) O plano deste livro acompanha nossa definição de organizações como unidades sociais que procuram atingir objetivos específicos. (Etzioni, 1973:9-11)

Interessante notar que o autor acima revela a preocupação em prover um programa de investigação (expresso na ideia de "plano de livro") derivado dos qualificadores do conceito de organização definido por ele. Isso é fundamental tendo-se em conta que o autor endereça seu texto para uma audiência específica, que irá receber suas ideias ou não, dependendo da compatibilidade destas com seu campo semântico referencial, mesmo que, nestas ideias, exista algo novo. Neste caso, a orientação teleológica da organização tal qual definida acima reforça o entendimento de que o paradigma fundador dos teóricos organizacionais é o funcionalista: ao definir "organização", o autor se preocupa em atribuir qualificadores estruturais distintos deste objeto, que sejam capazes de representar esta entidade universalmente, a despeito das especificidades de cada caso empírico. O autor do trecho anterior, o sociólogo Amitai Etzioni, indica ainda ser sua conceituação referida à definição de Talcott Parsons, o grande mentor do funcionalismo sociológico desta época. Realmente, Parsons é lembrado por muitos revisionistas do campo de estudos organizacionais como a grande referência intelectual da área naquele período (Burrell e Morgan, 1979), já que, mesmo tendo em conta a relevância do conceito weberiano de burocracia sobre os teóricos organizacionais, o acesso a este conceito se deu via Parsons e sua interpretação à obra do célebre sociólogo alemão.

Apesar de haver certo grau de integração neste grupo, os esforços dos teóricos da organização não foram ausentes de debate interno. Isso porque, ainda que servindo-se de um mesmo quadro lexical de referência (o léxico do funcionalismo sociológico [Burrell e Morgan, 1979]), havia entre os autores diferentes interpretações sobre este objeto, que se manifestavam nos diferentes conceitos de "organização" feitos à época. Quase sempre, as diferenças entre as definições eram demarcadas por alterações sintagmáticas do conceito, ou seja, outro conceito ou termo ao qual se recorria para delimitar os pontos essenciais daquela definição. Isso pode ser observado pelo trecho seguinte, retirado de outro conhecido texto da época: 
Contrastando com a organização social que aparece sempre que os seres humanos vivem juntos, existem organizações estabelecidas, deliberadamente, para um certo fim. (...) Como a característica distinta dessas organizações é a de que elas foram formalmente estabelecidas com o propósito explícito de conseguir certas finalidades, usa-se o termo "organizações formais" para designá-las. (Blau e Scott, 1979:17)

Etzioni, por sua vez, procurou posicionar-se criticamente ao qualificador "formal", como sugere a seguinte passagem: "Organização formal refere-se a um conjunto de características de organizações. Discutimos, adiante, esse aspecto; aqui, basta dizer que essa expressão não se refere a uma organização como uma entidade, mas apenas a uma parte dela" (Etzioni, 1973:10). Na verdade, além do qualificador "formal" apresentado por Blau e Scott (1979), outros termos também foram incluídos pelos sociólogos envolvidos neste debate léxico, tais como "organizações modernas" e "organizações complexas".

Outro aspecto referente à delimitação do campo pode ser identificado pela definição de "organização formal" apresentada acima. Visando qualificar melhor o conceito de "organização", essa definição também delimita as especificidades entre o objeto de investigação do teórico organizacional daquele do teórico social. Para isso, os autores contrapõem ao conceito de "organização formal" (objeto da sociologia das organizações) o conceito de "organização social" (objeto das ciências sociais como um todo). Também encontramos nesse qualificador a medida para o contraponto com outras dimensões da organização, como a ideia de "organização informal" (Blau e Scott, 1979).

\section{Considerações finais}

A motivação para o desenvolvimento deste ensaio, conforme apontamos anteriormente, diz respeito à necessidade de consideração das circunstâncias sociais e históricas que condicionam a criação, o empréstimo, o uso e a comunicação de conceitos nos campos científicos, em particular o campo de estudos organizacionais. Como lembram Clegg e Hardy (1998:30), o campo de estudos organizacionais é caracterizado, em parte, por uma série de "conversações progressivas, com vocabulários e termos gramaticais emergentes e com vários graus de descontinuidade". Conversações estas as quais buscam descrever, analisar, refletir, compreender, interpretar, representar - entre tantas outras possibilidades de estudo - as fronteiras, regras, histórias, recursos, dimensões, atributos, agentes, entre outros elementos caracterizadores das organizações. E, ao interpretar, os pesquisadores de organizações também participam dos processos de formação do léxico da área.

Entretanto, conforme as reflexões aqui realizadas, o próprio conceito que dá origem à área — o conceito de "organizações" - muitas vezes é utilizado com base em definições que desconsideram a natureza sincrônica e diacrônica das condições sociais e históricas que condicionam seu uso. Desconsidera-se, portanto, no tratamento dado a este e a outros conceitos 
centrais para a compreensão dos fenômenos que a área se propõe estudar, a necessidade de compreender as limitações inerentes à interpretação de estruturas mentais atuais em relação a fenômenos e conceitos de contextos sociais e/ou históricos distintos.

Ao mesmo tempo, chamamos a atenção para a importância da construção do léxico especializado na legitimação dos campos científicos e para a necessidade de respeitar os fenômenos linguísticos dinâmicos e criativos característicos da linguagem humana por meio da harmonização linguística, objetivos aparentemente conflitantes se consideradas as condições de formação, uso e disseminação de conceitos em ciências sociais. Entretanto, em lugar de abandonar iniciativas úteis de legitimação e consolidação do campo de estudos organizacionais, defendemos a necessidade do não abandono da capacidade reflexiva dos pesquisadores — individualmente e também como comunidade científica —, principalmente em relação aos aspectos aqui levantados: (i) a produção do conhecimento é uma atividade social que pressupõe compartilhamento de significados e domínio de uma linguagem da área; (ii) o problema da definição terminológica e da conceituação deve ser seriamente considerado das perspectivas social e histórica, e considerando-se a natureza sincrônica e diacrônica dos conceitos; (iii) novos fenômenos demandam a construção criativa e dinâmica de novos conceitos, capazes de dar conta da realidade; (iv) o léxico de uma área em construção, tal qual se configura a área de estudos organizacionais, deve ser objeto de reflexão e estudo, na medida em que reflete modificações nas formas de apreensão, representação simbólica e comunicação dos fenômenos estudados e dos sentidos a eles atribuídos.

Quanto a uma agenda de pesquisa sobre a perspectiva social e histórica dos conceitos em estudos organizacionais, propomos algumas frentes de trabalho, a saber:

v Críticas teórica, social e historicamente fundamentadas sobre a natureza sincrônica e diacrônica dos conceitos elementares da área de estudos organizacionais;

v Estudos terminológicos das características semânticas desses conceitos de acordo com quadros teóricos e/ou áreas de conhecimento distintos(as);

v Estudos comparativos das variantes terminológicas da área de estudos organizacionais, com foco na influência de espaços socioculturais e linguísticos específicos sobre o surgimento dessas variantes;

v Propostas de revisão crítica da terminologia da área de estudos organizacionais, com o objetivo de sugerir novas categorias, ampliações, reduções ou reformulações conceituais;

v Estudos de recepção de conceitos em contextos e em épocas distintas;

จ Estudos da criação, uso e reformulação de termos sintagmáticos na área de estudos organizacionais;

v Estudos de termos usados para designar diferentes fenômenos; de termos distintos que se referem ao mesmo fenômeno, de termos que apresentam diferentes graus de abstração ao se referirem a fenômenos inter-relacionados. 
Por fim, ressaltamos que o pressuposto central deste trabalho é que a definição de conceitos é uma prática essencial na formação de um campo acadêmico científico. Os conceitos são elementos centrais da referência lexical que articula o saber e a prática científica. Estes não podem ser propriamente definidos sem o cuidado com seu conteúdo diacrônico — todo conceito carrega uma trajetória passada de transformação, que reflete seus usos e o próprio intercâmbio social (que indica, na verdade, a história do sujeito que se expressa pela linguagem). Além disso, o membro da comunidade científica deve reconhecer que os conceitos representam importantes mecanismos linguísticos de intersubjetividade - eles carregam em si uma dimensão sincrônica, ou seja, são referências de significação que atendem a uma mesma comunidade linguística. Quando essas duas dimensões não são propriamente reconhecidas no fazer científico, este não assume sua principal condição de possibilidade: o saber reflexivamente orientado, capaz de promover o entendimento da sociedade e de nós mesmos.

\section{Referências}

AKTOUF, O. O simbolismo e a cultura de empresa: dos abusos conceituais às lições empíricas. In: CHANLAT, J.F. (Coord.). O indivíduo na organização. São Paulo: Atlas, 1994. v. 2.

ALVES, I.M. A renovação lexical nos domínios de especialidade. Revista da Sociedade Brasileira para o Progresso da Ciência: Terminologia, v. 58, n. 2, p. 32-34, 2006.

BIDERMAN, M.T.C. As ciências do léxico. In: OLIVEIRA, A.M.P.P.; ISQUERDO, A.N. (Org.). As ciências do léxico. 2. ed. Campo Grande: ED. UFMS, 2001. p. 13-22.

BLAU, P.; SCOTT, R.W. Organizações formais. São Paulo: Atlas, 1979.

BOUDON, R.; BOURRICARD, F. Organização. In: Paulo: Ática, 1993. p. 408-414.

. Dicionário crítico de sociologia. São

BURRELL, G.; MORGAN, G. Sociological paradigms and organisational analysis: elements of the sociology of corporate life. London: Heinemann Educational Books, 1979.

CLEGG, S.R.; HARDY, C. Introdução: organização e estudos organizacionais. In: (Org.). Handbook de estudos organizacionais: modelos de análise e novas questões em estudos organizacionais. São Paulo: Atlas, 1998. v. 1, p. 27-57.

DURKHEIM, E. As regras do método sociológico. São Paulo: Martins Fontes, 1995.

ETZIONI, A. Organizações modernas. São Paulo: Atlas, 1973.

FARIS, R.E.L. Organização social (sociologia). In: SILVA, B. (Coord.). Dicionário de ciências sociais. Rio de Janeiro: Fundação Getulio Vargas, 1986. v. 2, p. 847-848.

FAULSTICH, E. A socioterminologia na comunicação científica e técnica. Ciência e Cultura, v. 58, n. 2, p. 27-31, 2006.

FOUCAULT, M. As palavras e as coisas. São Paulo: Martins Fontes, 1999. 
FRANCISCONI, K. Configuração estrutural do campo científico em estudos organizacionais no Brasil: o período de 1997-2007. Tese (doutorado) — Setor de Ciências Sociais Aplicadas, Universidade Federal do Paraná, Curitiba, 2008.

GADAMER, H.G. Verdade e método. Petrópolis: Vozes, 1997. v. I

GELLNER, E.A. Conceito. In: SILVA, B. (Coord.). Dicionário de ciências sociais. Rio de Janeiro: Editora da FGV, 1986.

GOODE, W.J.; HATT, P.K. Métodos em pesquisa social. 7. ed. São Paulo: Nacional, 1979.

HOEBEL, E.A. Organismo. In: SILVA, B. (Coord.). Dicionário de ciências sociais. Rio de Janeiro: Fundação Getulio Vargas, 1986. v. 2, p. 841-842.

JASMIN, M.G. História dos conceitos e teoria política e social: referências preliminares. Revista Brasileira de Ciências Sociais, v. 20, n. 57, p. 27-38, 2005.

KOSELLECK, R. Uma história dos conceitos: problemas teóricos e práticos. Estudos Históricos, Rio de Janeiro, v. 10, p. 134-146, 1992.

KRIEGER, M.G.; FINATTO, M.J.B. Introdução à terminologia: teoria \& prática. São Paulo: Contexto, 2004.

LÓPEZ, F.S. Organismo Social. In: SILVA, B. (Coord.). Dicionário de ciências sociais. Rio de Janeiro: Fundação Getulio Vargas, 1986. v. 2, p. 842-843.

MORRIS, H.S. Organização social (antropologia). In: SILVA, B. (Coord.). Dicionário de ciências sociais. Rio de Janeiro: Fundação Getulio Vargas, 1986. v. 2, p. 846-847.

RAMOS, A.G. A nova ciência das organizações. 2. ed. Rio de Janeiro: FGV, 1989.

REY, A. Introduction: defining "definition". In: SAGER, J.C. Essays on definition: terminology and lexicography research and practice. The Netherlands: John Benjamins Publishing Company, 2000. p. 1-14.

RIOS, J.A. Organização. In: SILVA, B. (Coord.). Dicionário de ciências sociais. Rio de Janeiro: Fundação Getulio Vargas, 1986. v. 2, p. 848-850.

SAGER, J.C. Essays on definition: terminology and lexicography research and practice. The Netherlands: John Benjamins Publishing Company, 2000.

SELTTIZ, C. et al. Métodos de pesquisa nas relações sociais. São Paulo: EPU, 1974.

TSOUKAS, H.; KNUDSEN, C. Introduction: the need for meta-theoretical reflection in organization theory. In: The Oxford handbook of organization theory. Oxford; New York: Oxford University Press, 2003. p. 1-36.

VIZEU, F. Management no Brasil em perspectiva histórica: o projeto do Idort nas décadas de 1930 e 1940. Tese (doutorado) — Escola de Administração de Empresas de São Paulo, Fundação Getulio Vargas, São Paulo, 2008. 
. Potencialidades da análise histórica nos estudos organizacionais brasileiros. Revista de Administração de Empresas, v. 50, n. 1, p. 36-46, 2010.

WAHRLICH, B.S. Uma análise das teorias de organização. 5. ed. Rio de Janeiro: FGV, 1986.

WHETTEN, D.A.; FELIN, T.; KING, B.G. The practice of theory borrowing in organizational studies: current issues and future directions. Journal of Management, v. 35, n. 3, p. 537-563, 2009.

Queila Regina Souza Matitz é professora do Programa de Mestrado e Doutorado em Administração da Universidade Positivo. E-mail: queila.matitz@gmail.com.

Fabio Vizeu é professor do Programa de Mestrado e Doutorado em Administração da Universidade Positivo. E-mail: vizeu@up.com.br. 